\title{
Dynamic Characteristics Analysis of Ice-Adhesion Transmission Tower-Line System under Effect of Wind-Induced Ice Shedding
}

\author{
Yongping Yu ${ }^{1}$, Lihui Chen ${ }^{1}$, Juanjuan Wang ${ }^{1}$ and Guoji Liu ${ }^{2, *}$ \\ ${ }^{1}$ College of Construction Engineering, Jilin University, Changchun, 130021, China \\ ${ }^{2}$ College of Physics, Jilin University, Changchun, 130012, China \\ ${ }^{*}$ Corresponding Author: Guoji Liu. Email: liugj@jlu.edu.cn \\ Received: 17 April 2020; Accepted: 10 August 2020
}

\begin{abstract}
The tower line system will be in an unsafe status due to uniform or uneven fall of ice coating which is attached to the surface of tower and lines. The fall of ice could be caused by wind action or thermal force. In order to study the dynamic characteristics of the self-failure of the transmission line under the action of dynamic wind load, a finite element model of the two-span transmission tower line system was established. The birth and death element methods are used to simulate the icing and shedding of the line. Tensile failure strength is the shedding criterion for ice coating. The fluctuating wind speed time history of the tower line system is first simulated, and then the fluctuating wind and the average wind are superimposed to generate the instantaneous wind speed and converted into wind load. The dynamic response of the transmission tower line system under iced coupling with different wind speeds and different thicknesses of ice coating was studied. This is the first attempt that the coupling dynamic response of the icing shedding and wind load for the transmission tower-line system is discussed in this paper. In addition, the dynamic characteristics of wind are included. In particular, the limiting mechanical conditions are considered. According to the simulation results, it is found: because of the ice shedding, the stress of the conductor changes obviously in the first 20 seconds, and the ground wire changes sharply in the first two seconds; the icing of the conductor (ground) wire is gradually deicing under the action of wind vibration; the displacement of tower top increases with the increase of wind speed and icing thickness.
\end{abstract}

Keywords: Tower line system; fluctuating wind; ice shedding; dynamic response; wind-induced ice shedding

\section{Introduction}

At present, the operation status of long-distance ultra-high voltage (UHV) transmission lines mainly based on overhead transmission lines is closely related to the external meteorological conditions. Most transmission lines are built in the wild, often passing through mountains and plains, and exposed to the external environment for a long time. It is inevitable to suffer from

This work is licensed under a Creative Commons Attribution 4.0 International License, which permits unrestricted use, distribution, and reproduction in any medium, provided the original work is properly cited. 
the continuous impact of the natural environment, including lightning strike, temperature change, strong wind, freezing rain, conductor icing and the weight of overhead line. Under the influence of these factors, the line will be overloaded to cause wire breakage, collapse, etc., and may also cause the vibration of the tower-line system and the fatigue damage of the various components of the structure even its strength decreasing. There are various forms of safety accidents occurring on the line, but all of them affect the normal operation of the line and are not conducive to the safety of the power grid.

Ice is formed when moisture in the air or rainfall freezes on the surface of the structure. In practical engineering, the density, thickness, shape, type and position of icing will change with time, and the ice attached to the tower line system will shed evenly or unevenly when subjected to external forces such as wind load, natural melting or artificial de-icing. Based on the analysis of all kinds of ice accidents on transmission lines, the safety accidents caused by icing can be divided into the following categories:

(1) Due to the excessive thickness of the icing, the amount of icing exceeds the ultimate load that transmission lines can bear, resulting in wire breakage, foundation subsidence, collapse of transmission tower, wire flashover and so on.

(2) The instantaneous uniform or uneven de-icing of the line is to jump and cause the wire to be broken or short-circuited, and the insulator and the crossarm collide to cause damage.

(3) The uneven ice-covered line will gallop under the action of wind force. The galloping of transmission lines is an important factor affecting the safety of transmission lines in power grid for a long time. It can cause the transmission lines to trip, the bolts of the cross-arm of the tower to fall off and damage to the tower cross-arm, jumping line, insulator and fittings, which make the operation situation of the power grid extremely severe.

In the following section, the methods of field measurement, physical experiments, numerical simulation and the model of coupling effect of wind load and icing investigating dynamical characteristics of ice-adhesion transmission tower-line system under effect of wind-induced ice shedding will be reviewed.

\subsection{Field Measurements and Physical Experiments of Wire Icing and Icing Shedding}

McComber et al. [1] carried out field measurements of two transmission lines on Laurentian Mountain, Quebec City, Canada. The elevation of the line is $902 \mathrm{~m}$ and the span of the line is $96.5 \mathrm{~m}$ and $32.6 \mathrm{~m}$, respectively. The maximum ice thickness of the two conductors is $35 \mathrm{~mm}$ and $8 \mathrm{~mm}$, respectively. The conclusion shows that the icing degree of the conductors is closely related to the elevation and wind speed, the final icing load is well predicted by temperature, wind speed and the icing rate. Druez et al. [2] studied the icing and deicing process of conductors, described the icing shedding as melting, sublimation and mechanical vibration deicing of conductors. The effects of five factors on deicing were studied: average wind speed in deicing process, initial icecovering quality, average temperature in deicing process, average temperature and average wind speed in the process of deicing, and average temperature and average wind speed in the process of ice-covering formation. Savadjiev et al. [3] recorded 57 icing events at the test site in Quebec, Canada, and obtained the relationship between the icing rate of conductors and meteorological conditions such as environmental temperature, wind direction and wind speed of wind load, freezing rain and precipitation rate.

Morgan et al. [4] firstly studied icing and deicing of transmission lines. In 1964, the icing shedding was simulated by applying the method of concentrated load. A series of experiments 
on icing shedding were made, and the jumping height of the de-icing lines were studied. In order to study the static and dynamic effects of ice shedding on the tower, Jamaleddine et al. [5] have carried out a series of laboratory tests on a two-span scale device, which has two horizontal and equal spacing and is suspended in the middle by an insulator string. In these experiments, the ice load is simulated by dropping a dead weight suddenly from the conductor. At the same time, a nonlinear finite element model is established by ADINA. The static and transient responses of the physical model are simulated numerically. The predicted results are compared with the experimental results of a typical case. The comparison shows that ADINA has good performance in simulating the static and transient dynamic response of this highly nonlinear engineering phenomenon. Meng et al. [6] has established a full-scale multi-span physical model to simulate icing by using concentrated loads suspended on conductors, and the actual dynamic response of conductor displacement and tension under different deicing modes is obtained. In addition, a multi-span and multi-degree-of-freedom dynamic model is established for the analysis of ice shedding. The calculated results are in good agreement with the experimental results, which proves the validity of the application of concentrated load in the test and the numerical simulation program.

\subsection{Numerical Simulation of Icing Shedding in Transmission Tower-Line System}

McClure et al. [7] conducted shape finding analysis on transmission lines, and studied the dynamic response of transmission lines under external excitations such as sudden failure of the structure and de-icing impact load. The damage criterion of icing was defined by Kálmán et al. [8] in 2003. The dynamic analysis of icing shedding during mechanical deicing was studied, and the applicability of the damage criterion was discussed. Mirshafiei et al. [9] used equivalent density to simulate line icing, and the phenomenon of deicing when conductor and ground line was broken was studied. Du et al. [10] established the finite element model of 4 towers and 5 spans transmission line by numerical method, and simulated the ice with the additional ice element method. The dynamic response of the structure was analyzed when the ice on the middle span conductor fell off at the same time, different time and different thickness. The results show that the maximum rebound height, unbalanced tension and wire tension caused by ice shedding at one time are $24 \%, 17 \%$ and $14 \%$ lower than those caused by ice shedding at different times. The effects of damping ratio, deicing ratio, shedding method and ice thickness on the dynamic response of the insulator jump height, unbalanced tension and vertical load after icing off were discussed by Yang et al. [11]. According to the results, the design values of unbalanced tension and vertical load of UHV suspension tower in large area covered by ice were proposed. Yan et al. [12] proposed a numerical simulation method for transmission line icing and deicing. The dynamic response of multi-span transmission lines under the influence of span length, span number, elevation difference between icing span and suspension end, length of suspension insulator string, number of secondary conductors in split conductors and conductor types was analyzed. A three-dimensional finite element model of the transmission tower-line coupling system was established by Zhang et al. [13]. The dynamic responses of the tower-line coupling system under different wind speeds and directions were investigated. An failure criterion for icing of conductors shedding is proposed to study the transient dynamics of line systems subjected to shock loads by $\mathrm{Ji}$ et al. [14]. Then, considering the effect of the initial natural ice shedding, the ice shedding induced by initial shocks in finite element analysis was studied by Ji et al. [15]. 


\subsection{Coupling Effect Studies of Wind Load and Icing}

AI-Bermani et al. [16] simulated and predicted the ultimate strength and behavior of transmission towers under static load conditions. Hartog [17] proposed the galloping theory for the first time to explain the obvious vibration mechanism of iced conductor caused by wind load, and the size of spacing and tension in conductor do not affect the galloping principle characteristics. Through numerical experiments, Du et al. [18] established finite element model to analyze the dynamic response of transmission line system with and without icing shedding when galloping occurs across the mid-span conductor, and studied the difference of two kinds of loads under different wind speeds. The results show that the unbalanced tension at the tower head and the transverse amplitude of the adjacent span increase with the increase of wind velocity. The transverse vibration frequency of adjacent transverse conductors caused by ice shedding increases obviously and the vertical rebound height decreases relatively. Tian et al. [19] and Fu et al. [20] studied the failure mechanism of the tower under extreme wind load from full-scale test and finite element numerical simulation. The loads are applied through riggings of reaction frames in full-scale test. Tian et al. [21] established the finite element model of the power transmission towers to simulate its failure process subjected to broken-line load and wind-ice load, respectively. A good agreement of the simulated results was found in comparison with experimental results. The influences of the wind velocity and ice thickness on aerodynamic parameters and conductor galloping were investigated by $\mathrm{Lu}$ et al. [22]. Rezaei et al. [23] proposed a structural reliability analysis of transmission lines considering the uncertainties of climatic variables such as, wind speed, ice thickness and wind angle, and of the resistance of structural elements. Based on a nonlinear finite element method, Yan et al. [24] discussed the galloping of iced bundle conductor transmission lines in steady and stochastic wind fields, respectively. Gani et al. [25] pointed out the importance of the dynamic response of guyed towers for transmission lines under wind loading. The simplified static-equivalent method was applied and compared with the transient dynamic analysis employing finite element method, considering loading two cases, bare and iced transmission lines structures. In transient dynamic analysis, the turbulent wind is considered and defined by its power spectral density (PSD). It was found that the static-equivalent method may underestimate the possible dynamic response. Kim et al. [26] established a lumped massspring-damper system to simulate galloping phenomenon with fluctuating wind velocity of the iced power transmission line. The fluctuating wind velocity was regenerated with time history by using Kaimal spectrum. Yang et al. [27] established finite element model and proposed the transforming density method and $10 \mathrm{~m} / \mathrm{s}$ of wind velocity to analyze the unbalanced tensions of UHV transmission towers in heavy icing areas. The wind loads were applied to the conductor nodes by the means of equivalent concentrated forces.

As mentioned, previous studies mainly focused on the dynamic response of tower-line system under wind load, icing shedding of the line or coupling response of the line icing and wind load. In this paper, the coupling dynamic response of the wire icing shedding and wind load for the three-towers-two-lines system with effect of dynamic characteristics of wind is considered. The fluctuating wind speed time history of the tower line system is converted into wind load. The tower line system is established, and the birth-death-element method is used to simulate the icing shedding of the line. The dynamic response of the transmission tower line system under iced coupling with different wind speeds and different thicknesses of icing is studied. 


\section{Finite Element Model of Tower-Line System}

\subsection{Engineering Background and Design Parameters}

The double circuit $500 \mathrm{kV}$ high-voltage DC transmission line overhanging corner tower in this paper is located in border area between Sichuan Province and Yunnan Province, China. The transmission towers have the height of $63 \mathrm{~m}$ with cross arm $30 \sim 54 \mathrm{~m}$ above ground. The corner degree of the conductors and ground wires are $3^{\circ} \sim 15^{\circ}$, and the standard span length is $500 \mathrm{~m}$. The transmission towers are angle steel towers. The material of main members is Q420 steel, and the material of other members is Q345 steel. The design wind speed at a reference altitude of $10 \mathrm{~m}$ is $27 \mathrm{~m} / \mathrm{s}$.

\subsection{Transmission Tower-Line System Modeling}

The three-dimensional finite element model of the two-span transmission tower-line system is established using ANSYS software and shown in Fig. 1. Ruling span is $500 \mathrm{~m}$, the angle of the line is 15 degrees, each conductor and ground wire are divided into 50 parts on average. The boundary conditions in transmission tower-line system: all degrees of freedom are constrained at the four base of transmission tower, and three degrees of freedom of rotation are constrained at each node of conductor and ground line. Ground wires are hinged with transmission towers, and insulators are hinged with conductors and transmission towers.

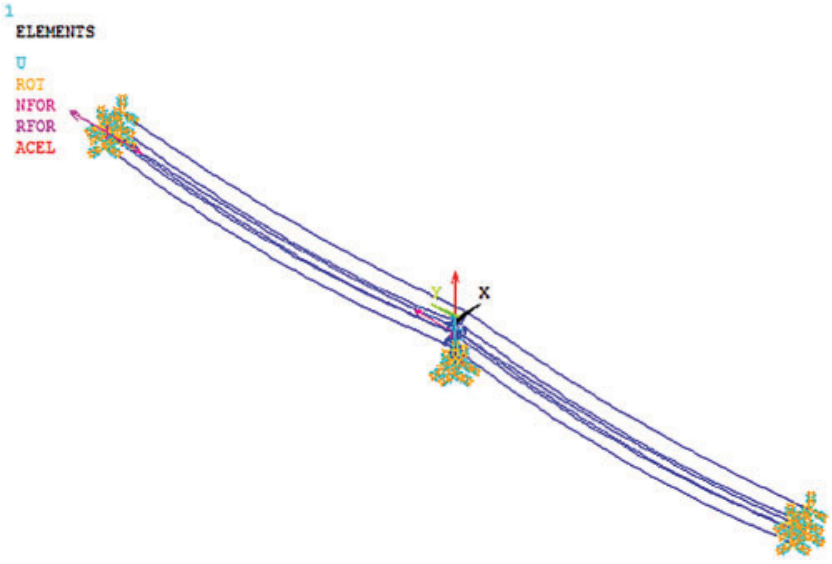

Figure 1: Finite element model of transmission tower-line system

\subsection{Tower Modeling}

The BEAM188 element is used in the finite element model of transmission tower, which has two nodes, and include six degrees of freedom at each node. It can be well applied to the analysis of linear and nonlinear large strain problems. The finite element model of transmission tower consists of 1,499 units, 547 nodes and 33 sectional types. The six degrees of freedom of the four legs of the tower are fully constrained. The detailed materials parameters are as follows: the elastic modulus is $2.06 \times 10^{5} \mathrm{MPa}$, the Poisson ratio is 0.3 , the density is $7850 \mathrm{~kg} / \mathrm{m}^{3}$. The finite element analysis model of the transmission tower is shown in Fig. 2, and the parameters of the main members of the transmission tower are listed in Tab. 1. 

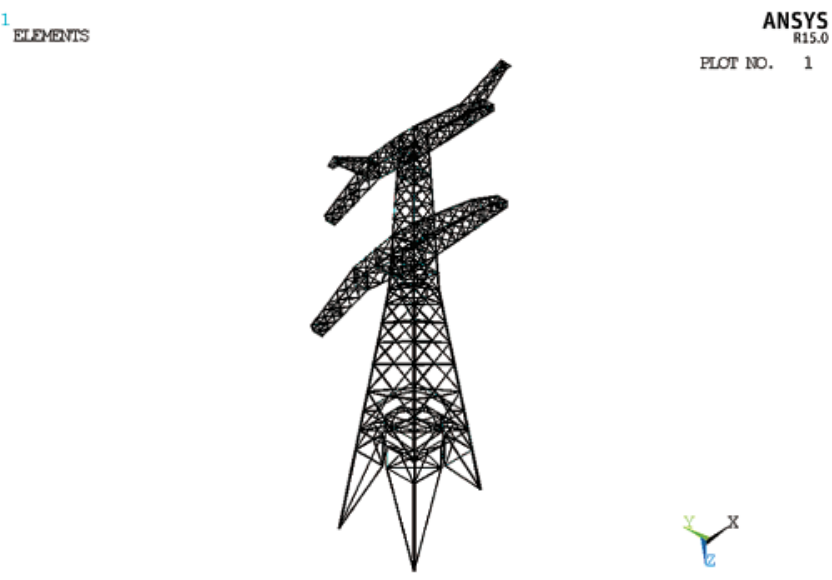

Figure 2: Finite element analysis model of the transmission tower

\subsection{Conductors and Ground Wires Modeling}

The transmission line is a typical flexible structure. It is subjected to tensile force under normal conditions but does not bear bending moment and pressure. It has high nonlinearity, small stiffness and large span. Therefore, it is usually treated as a cable structure. The LINK10 element is to simulate the conductor and ground wire in this paper. The LINK10 element with translational degrees of freedom in $\mathrm{X}, \mathrm{Y}$ and $\mathrm{Z}$ directions. When the element is compressed, its stiffness will disappear, which is used to simulate the relaxation of transmission lines.

At the initial moment, under the influence of its own gravity, the transmission line gradually reaches equilibrium from the relaxation state and produces a certain sag. In this process, a small initial strain is generated, which leads to the initial stress and tension in the transmission line. The initial shape and initial stress of the cable structure are two interacting and unknown quantities. To satisfy both the assumed initial geometry and the assumed initial stress, only iteration method can be used to find the shape of transmission line. In this paper, the direct iteration method is used to finding the shape of conductors and ground wires. The direct iteration method is to establish the finite element model in the direction of connecting the two suspension points, a very small initial strain of the element is given, the other parameters such as elastic modulus, density, and cross-sectional area employ actual values, and the self-weight load along the direction of arc is applied. Physical parameters of conductor and ground wire are shown in Tab. 2. The iteration calculation is carried out with the known horizontal tension of the transmission line as the convergence condition, and the finite element model is updated repeatedly. When the convergence condition is satisfied, the shape of the model is the initial shape of the transmission line under its own gravity.

\subsection{Icing Modeling}

In this paper, the method of additional ice element is used to simulate the icing. In the numerical simulation of icing, it is impossible to completely reflect the icing situation of transmission lines. Therefore, it is generally assumed that the icing uniformly distributes on the surface of transmission towers and lines, and the icing is equivalent to a hollow tube with equal thickness. The BEAM188 element is used to simulate icing, the simulation principle of icing is shown in Fig. 3. The sketch of transmission line icing is shown in Fig. 4. The interface between the icing and the conductor is simulated by using the conode of the icing element and the conductor. At 
present, scholars usually adopt the method of assuming icing thickness to describe conductor icing. The icing element is established after the shape of the wire construction. Then the static analysis is also carried out under the action of icing, in order to determine the final shape of the wire under the icing.

Table 1: Parameters of the main members of the transmission tower

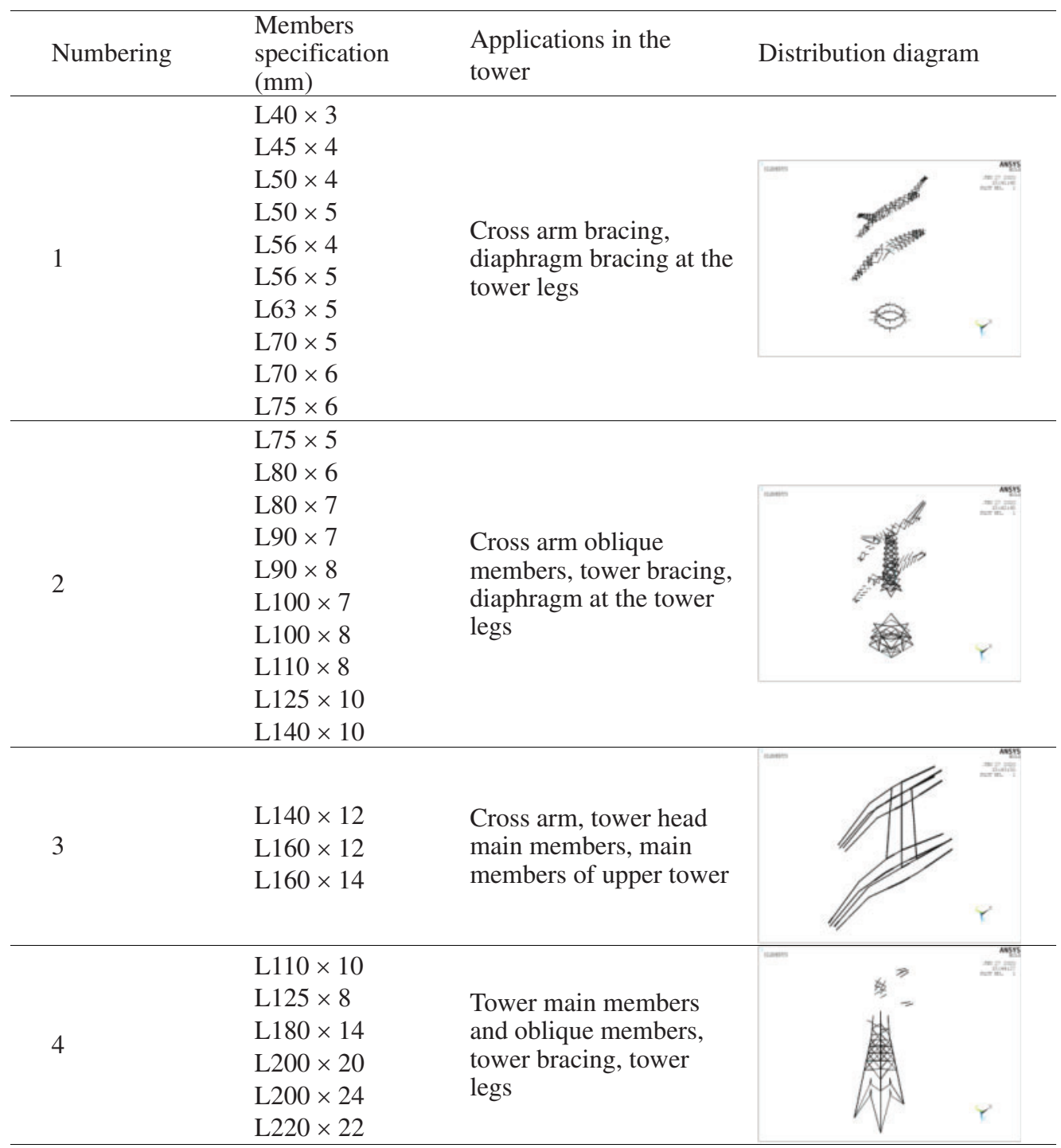

Petrovic [28] and Druez et al. [29] studied the mechanical properties of icing and obtained some mechanical parameters: Young's modulus is $9.7-11.2 \mathrm{GPa}$, Poisson's ratio is $0.29-0.32$, tensile strength is $0.7-3.1 \mathrm{MPa}$, and compressive strength is 5-25 MPa. In this paper, the criterion of tensile failure strength is adopted, elastic modulus $E=1.0 \times 10^{9} \mathrm{~N} / \mathrm{m}^{2}$, density $\rho=0.9 \times 10^{3} \mathrm{~kg} / \mathrm{m}^{3}$, tensile failure strength $\xi_{0}=0.9 \mathrm{MPa}$. 
Table 2: Physical parameters of conductor and ground wire

\begin{tabular}{lll}
\hline & Conductor LGJ-900/75 & Ground wire LBGJ-100-20AC \\
\hline Section area $\left(\mathrm{mm}^{2}\right)$ & 973.16 & 100.88 \\
Diameter $(\mathrm{mm})$ & 40.6 & 13 \\
Weight per unit length $(\mathrm{kg} / \mathrm{m})$ & 3.0672 & 0.674 \\
Young's modulus $(\mathrm{MPa})$ & 65380 & 139500 \\
Breaking force $(\mathrm{kN})$ & 219.74 & 121.66 \\
Maximum working stress $(\mathrm{MPa})$ & 92.10 & 482.78 \\
Average annual operating stress $(\mathrm{MPa})$ & 57.56 & 301.74 \\
Design safety factor & 2.5 & 2.5 \\
\hline
\end{tabular}

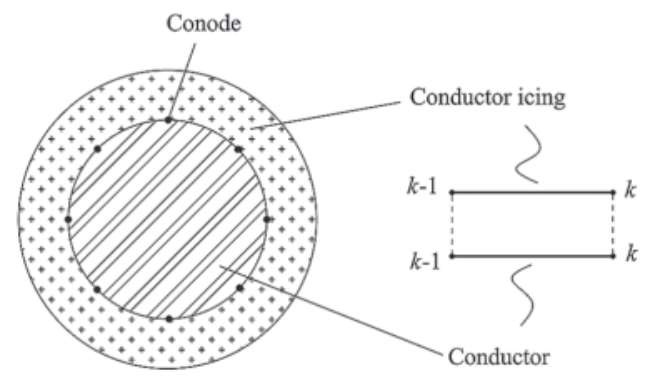

Figure 3: Simulating principle of icing element

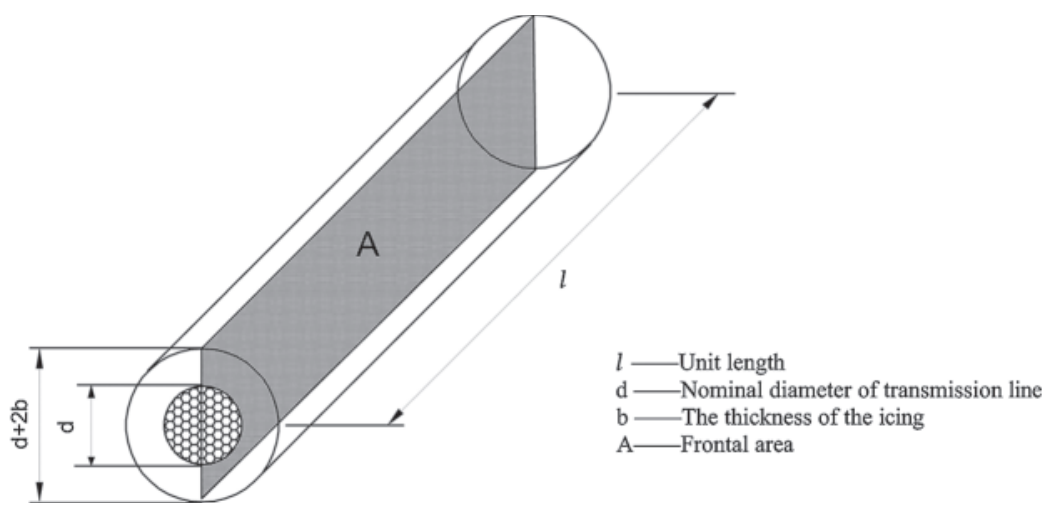

Figure 4: The sketch of transmission line icing

\section{Wind Load}

According to a large number of measured experiments and record analysis, the impact of near-earth wind on buildings can be divided into two parts: fluctuating wind and average wind. In this chapter, MATLAB is used to simulate the time history of the fluctuating wind speed of the tower line system. The fluctuating wind speed superimpose the average wind speed to get the instantaneous wind speed, and the instantaneous wind speed is converted to wind load. 
The total wind velocity at a point in the structure is:

$v(x, y, z, t)=\bar{v}(z)+v_{f}(x, y, z, t)$

where, $\bar{v}(z)$ is the mean wind speed, and its change period in structure is much larger than the natural vibration period of the structure, and the effect on the structure is static; $v_{f}(x, y, z, t)$ is the fluctuating wind, its change period in structure is smaller than the period of natural vibration of structure, and its effect on structure can be not simplified to static force, so dynamic action must be considered.

\subsection{Mean Wind}

In the atmospheric boundary layer, the wind velocity at the surface is zero, in general, because of the friction resistance of the surface morphology. With the increase of altitude, the influence of surface morphology on wind speed is gradually reduced, and the average wind speed is gradually increased. The effect of ground friction on wind speed is negligible at a height of $300-500 \mathrm{~m}$ above the ground. This change law is called the wind velocity gradient, or wind profile, as shown in Fig. 5. The gradient law of mean wind velocity can be expressed by exponential laws, as follows:

$\frac{\bar{v}}{\bar{v}_{\mathrm{S}}}=\left(\frac{z}{z_{\mathrm{S}}}\right)^{\alpha}$

where, $z_{s}$ is a reference altitude of $10 \mathrm{~m}, \bar{v}_{s}$ is mean wind velocity at reference altitude, $z$ is the altitude, $\alpha$ is ground roughness index and it is shown in Tab. 3. According to the environment of transmission tower, the topography category is B.

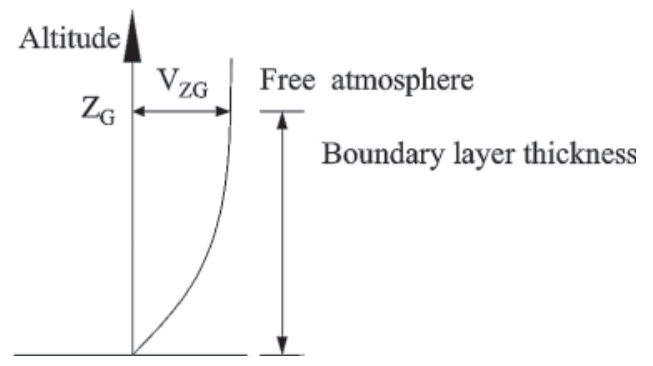

Figure 5: Mean wind profile

Table 3: Ground roughness index

\begin{tabular}{lllll}
\hline Ground roughness index & \multicolumn{4}{l}{ Topography category } \\
\cline { 2 - 5 } & A & B & C & D \\
\hline$\alpha$ & 0.12 & 0.16 & 0.22 & 0.3 \\
\hline
\end{tabular}

\subsection{Fluctuating Wind and Its Time-History Simulation}

The intensity of the pulsating wind changes with time. Many experts have studied the wind power spectrum and obtained different forms of pulsating wind velocity spectrum expressions. 
The Davenport [30] wind velocity spectrum expression is widely recognized:

$S_{v}(n)=4 k \bar{v}_{s}^{2} \frac{x^{2}}{n\left(1+x^{2}\right)^{\frac{4}{3}}}$

where, $x=\frac{1200 n}{\bar{v}_{s}} ; n$ is frequency $(\mathrm{Hz}) ; k$ is ground resistance coefficient.

The autoregressive model of linear filter method is used to simulate the fluctuating wind. $M$ related fluctuating wind velocity time histories $v_{f}(x, y, z, t)$ can be simulated by the following formula:

$v_{f}(x, y, z, t)=-\sum_{k=1}^{p} \psi_{k} v_{f}(x, y, z, t-k \Delta t)+N(t)$

where, $\psi_{k}$ is autoregressive coefficient matrix; $N(t)$ is $M$-dimensional independent normal distribution random process vector; $p$ is autoregressive order; $\Delta t$ is time step.

According to the environment of transmission tower-line system, the parameters related to fluctuating wind simulation are as follows: ground roughness coefficient $\alpha=0.12$, total time $t=100 \mathrm{~s}$, ground resistance coefficient $k=0.003$, time step $\Delta t=0.1 \mathrm{~s}$. The mean wind velocity at $10 \mathrm{~m}$ above the ground is selected from three grades, namely 10,15 and $27 \mathrm{~m} / \mathrm{s}$, respectively.

Due to the complex structure and many nodes of transmission tower line system, it is impossible to simulate the time history of pulsating wind at all points. According to the height and structural characteristics of the transmission tower, it is divided into 6 sections along the vertical direction, and the center of each section is a simulation point. The time history of fluctuating wind speed at each loading point can be obtained by calculating the wind speed at each section. The vertical division of sections on transmission tower is shown in Fig. 6, and the height of the simulation point and the windward area of transmission tower are listed in Tab. 4.

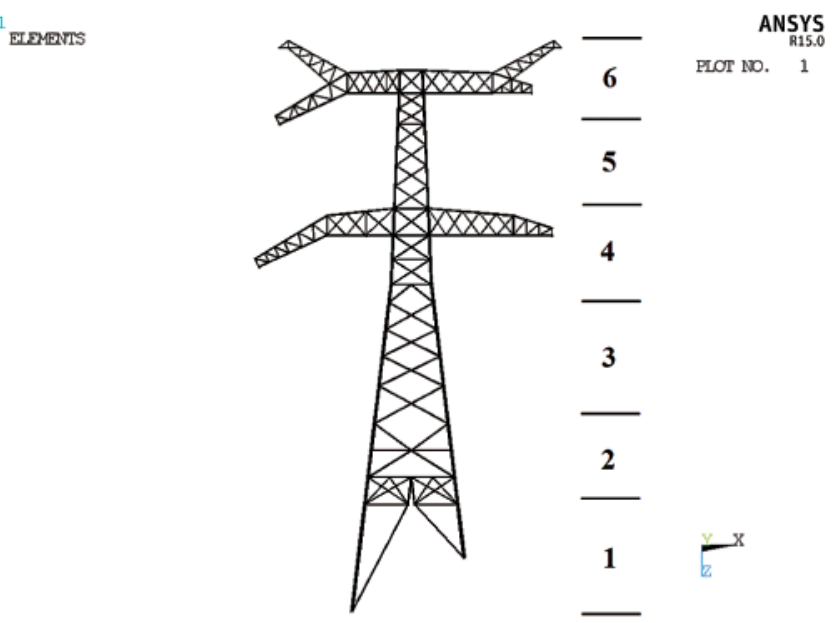

Figure 6: Vertical division of sections on transmission tower 
Table 4: Height of the simulation point and windward area of transmission tower

\begin{tabular}{lll}
\hline Segment numbering & The height of the simulation point $(\mathrm{m})$ & Projected area $\left(\mathrm{m}^{2}\right)$ \\
\hline 1 & 6.00 & 8.32896 \\
2 & 17.61 & 10.5365 \\
3 & 28.17 & 9.67178 \\
4 & 39.05 & 6.53141 \\
5 & 49.50 & 5.52828 \\
6 & 62.42 & 4.06778 \\
\hline
\end{tabular}

The time-history of fluctuating wind velocity of tower-line system can be obtained by Eq. (4). To save space, the time-history curve of fluctuating wind velocity at simulated point 6 (that is the top of the tower) when the wind velocity is $27 \mathrm{~m} / \mathrm{s}$ is given only, as shown in Fig. 7.

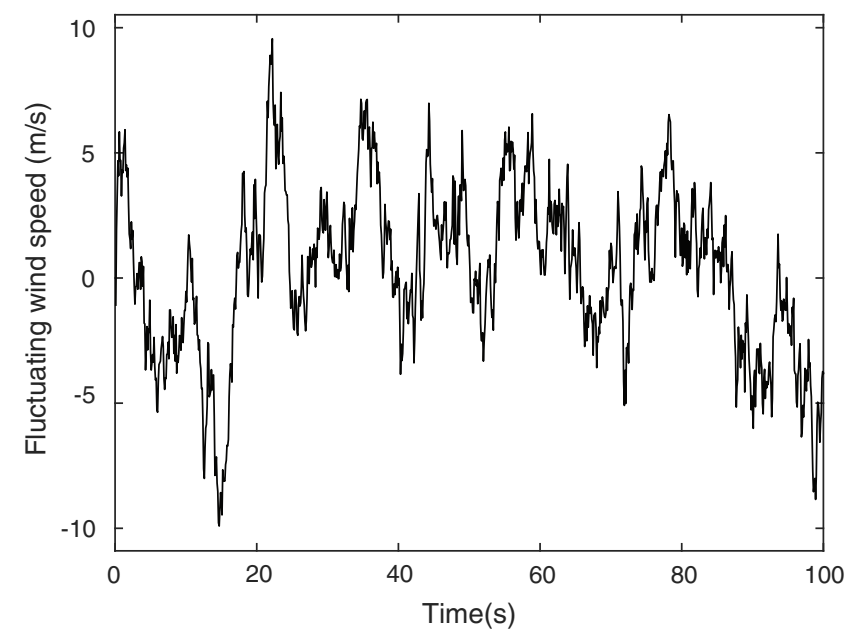

Figure 7: Time history of fluctuating

The accuracy of wind velocity time history simulation results directly affects the structural analysis of transmission tower line system. Therefore, the simulated fluctuating wind velocity should be tested. The most direct method is to compare the simulated pulsating wind velocity power spectrum characteristics with the target wind velocity spectrum (Davenport) curve calculating by Eq. (3) to see if the two curves are consistent. Fig. 8 shows the comparison between the power spectrum characteristics of fluctuating wind velocity and the target wind velocity spectrum at simulated point 6 when the wind velocity is $27 \mathrm{~m} / \mathrm{s}$. From the Fig. 8, it can be seen that the power spectrum characteristics of simulated fluctuating wind velocity coincide with the target power spectrum curve very well, which verifies the validity and rationality of the program compiled by autoregressive method. That is to say the time history of simulated fluctuating wind velocity in this paper conforms to the real law and can be applied to structural analysis.

\subsection{Simulation of Wind Load}

The near-earth wind is composed of mean wind and fluctuating wind. Therefore, the wind velocity time course of the near-earth wind should also be added with the mean wind. The mean 
wind velocity is calculated by using Eq. (2), the wind load time history of tower-line system can be calculated by Eqs. (5) and (6) after adding the two parts together.

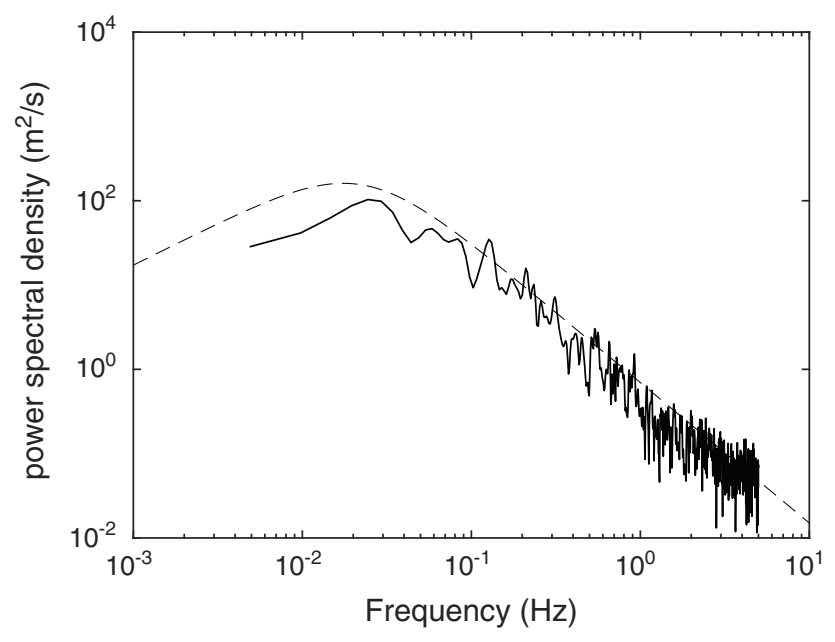

Figure 8: Comparison of power spectrum wind velocity

The wind load calculation formula of transmission tower is as follows:

$F=\mu_{s} A_{s} V(t)^{2} / 1.63$

where, $\mu_{s}$ is the shape coefficient of structural components, take $2.5 ; A_{S}$ is windward area of transmission tower $\left(\mathrm{m}^{2}\right) ; V(t)$ is near-earth wind velocity with reference altitude of $10 \mathrm{~m}(\mathrm{~m} / \mathrm{s})$.

The calculation formula of transmission line wind load is as follows:

$W_{L}=\alpha \mu_{s c} \beta_{c} A \mu_{z} V(t)^{2} \sin ^{2} \theta / 1.6$

where, $\alpha$ is the inhomogeneity coefficient of wind pressure, the value is shown in Tab. 5; $\mu_{s c}$ is wire shape coefficient, when the wire diameter less than $17 \mathrm{~mm}$ or ice cover (regardless of wire diameter) should be taken $\mu_{s c}=1.2$, when the diameter is greater than or equal to $17 \mathrm{~mm}$, take $\mu_{s c}=1.1 ; \beta_{c}$ is the adjustment coefficient of wind load, the value under different wind speed conditions is shown in Tab. $5 ; A$ is the windward area of transmission lines; $\mu_{z}$ is the height coefficient of wind pressure, according to class B of ground roughness, the values are shown in Tab. $6 ; \theta$ is the angle between the wind and conductor direction.

Table 5: Wind pressure non-uniformity coefficient $\alpha$ and wind load adjustment coefficient $\beta_{c}$

\begin{tabular}{lllll}
\hline Wind speed $V(\mathrm{~m} / \mathrm{s})$ & $V<20$ & $20 \leq V<27$ & $27 \leq V<31.5$ & $V>31.5$ \\
\hline$\alpha$ & 1.00 & 0.85 & 0.75 & 0.70 \\
$\beta_{c}$ & 1.00 & 1.10 & 1.20 & 1.30 \\
\hline
\end{tabular}

The wind load time history of each simulation point of the transmission tower line system can be obtained by Eqs. (5) and (6). Due to space limitations, only the wind load time history curve at simulated point 3 (the middle part) and simulated point 6 (the top of the transmission tower) are given in Fig. 9. 
Table 6: Height variation factor of wind pressure

\begin{tabular}{llllllllll}
\hline Height above ground (m) & 5 & 10 & 15 & 20 & 30 & 40 & 50 & 60 & 70 \\
\hline$\mu_{z}$ & 1.00 & 1.00 & 1.14 & 1.25 & 1.42 & 1.56 & 1.67 & 1.77 & 1.86 \\
\hline
\end{tabular}

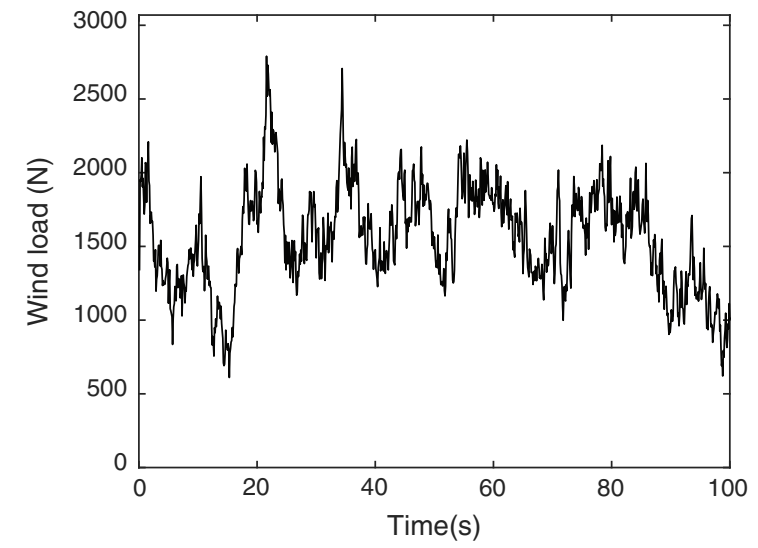

(a)

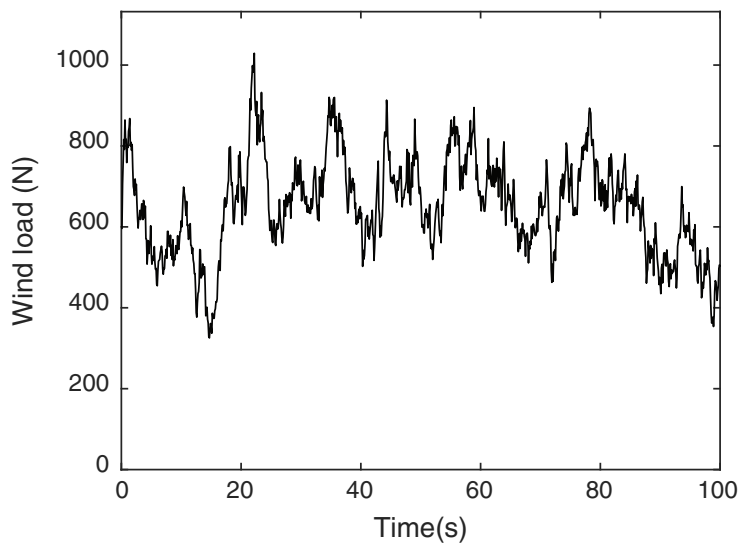

(b)

Figure 9: Wind load time history. (a) The middle part of the tower. (b) The top of the tower

\section{Theory of Wind-Induced Ice Shedding in Finite Element Analysis}

\subsection{The Incremental Equilibrium Equation of Nonlinear Dynamic Analysis}

Because of the large deformation of the transmission tower line system, geometric nonlinearity must be considered in the dynamic response calculation. The derivation of the equation is as follows:

(1) Discretization of continuous region and construction of interpolation function:

The solution domain is discretized with isoparametric elements, and the interpolation function of displacement within the element can be expressed as:

${ }^{t} u_{i}=\sum_{k=1}^{n} N_{k}{ }^{t} u_{i}^{k} \quad(i=1,2,3)$

where, $N_{\mathrm{k}}$ is the interpolation function corresponding to nodal point, ${ }^{t} u_{i}^{k}$ is the displacement component of nodal point $k$ corresponding to direction $i$ at time $t, n$ is the number of element nodal points.

It can be expressed as a matrix

${ }^{t} \mathbf{U}=\mathbf{N}^{t} \mathbf{u}$

(2) The solution equation of the dynamic system:

The configuration at time $t$ is used as the reference point, the equilibrium equation at time $t+\Delta t$ is:

${ }^{t+\Delta t}{ }_{t} \sigma_{i j, j}+{ }^{t+\Delta t}{ }_{t} f_{i}-\rho{ }^{t+\Delta t} u_{i, t t}-\mu{ }^{t+\Delta t} u_{i, t}=0$ 
where, ${ }^{t+\Delta t}{ }_{t} \sigma_{i j}$ is Cartesian components of the 2nd Piola-Kirchhoff stress tensor, ", $j$ " is the partial derivative with respect to the independent coordinate $x_{j}$, the subscript " $i j, j$ " satisfy summation convention; ${ }^{t+\Delta t} f_{i}$ represents the component of the volume force per unit volume in the $i$ direction; $\rho$ is mass density, $\mu$ is damping coefficient; ${ }^{t+\Delta t} u_{i, t t}$ and ${ }^{t+\Delta t} u_{i, t}$ represents the acceleration and velocity in the $i$ direction respectively. All the variables correspond to the configuration at time $t+\Delta t$ but measured in the configuration at time $t$.

The boundary condition of the force is:

${ }^{t+\Delta t} \sigma_{i j} n_{j}={ }^{t+\Delta t} \bar{T}_{i}$

where, $n_{j}$ is the direction cosine of the normal line outside the boundary, ${ }^{t+\Delta t}{ }_{t} \bar{T}_{i}$ is the surface force at the boundary.

Galerkin's formulation in the equivalent integral form of the equilibrium equation and the boundary condition of the force can be expressed as:

$\int_{{ }^{t} V} \delta u_{i}\left({ }^{t+\Delta t}{ }_{t} \sigma_{i j, j}+{ }^{t+\Delta t}{ }_{t} f_{i}-\rho{ }^{t+\Delta t} u_{i, t t}-\mu{ }^{t+\Delta t} u_{i, t}\right){ }^{t} d V=\int_{{ }^{t} S_{\sigma}} \delta u_{i}\left({ }^{t+\Delta t}{ }_{t} \sigma_{i j} n_{j}-{ }^{t+\Delta t}{ }_{t} \bar{T}_{i}\right){ }^{t} d S$

where $\delta u_{i}$ is the variation of the current displacement component ${ }^{t+\Delta t} u_{i}$, that is, the variation from time $t$ to time $t+\Delta t$ of the displacement increment component $u_{i}$, where $u_{i}={ }^{t+\Delta t} u_{i}-{ }^{t} u_{i}$.

Integrate by parts for the first term of Eq. (11):

$\int_{{ }^{t} V} \delta{ }^{t+\Delta t}{ }_{t} \varepsilon_{i j}{ }^{t+\Delta t}{ }_{t} \sigma_{i j}+\delta u_{i} \rho^{t+\Delta t} u_{i, t t}+\delta u_{i} \mu^{t+\Delta t} u_{i, t}{ }^{t} d V=\int_{0} \delta u_{i}{ }^{t+\Delta t}{ }_{t} f_{i}{ }^{t} d V+\int_{{ }^{t} S_{\sigma}} \delta u_{i}{ }^{t+\Delta t}{ }_{t}{ }_{i}{ }^{t} d S$

where, ${ }^{t+\Delta t}{ }_{t} \varepsilon_{i j}$ in the above formulas is Green-Lagrange strain tensor. The stresses ${ }^{t+\Delta t}{ }_{t} \sigma_{i j}$ and strains ${ }^{t+\Delta t}{ }_{t} \varepsilon_{i j}$ are unknown.

To obtain the incremental equilibrium equation of dynamic analysis, the incremental decomposition of Kirchhoff stress tensor and Green strain tensor at time $t+\Delta t$ is introduced:

${ }^{t+\Delta t}{ }_{t} \sigma_{i j}={ }^{t} \tau_{i j}+{ }_{t} \sigma_{i j}$

${ }^{t+\Delta t}{ }_{t} \varepsilon_{i j}={ }_{t} \varepsilon_{i j}$

where, ${ }_{t} \sigma_{i j}$ and ${ }_{t} \varepsilon_{i j}$ are the increment of stress and strain from the configuration at time $t$ to the configuration at time $t+\Delta t$ respectively, ${ }^{t} \tau_{i j}$ is known Cartesian components of the Cauchy stress tensor.

It is assumed that the relationship of the increment of stress and the increment of strain is linear:

${ }_{t} \sigma_{i j}={ }_{t} D_{i j k l} \varepsilon_{k l}$

where, ${ }_{t} D_{i j k l}$ is the tangent constitutive tensor corresponding to the configuration at time $t$.

The Green strain increment is:

${ }_{t} \varepsilon_{i j}={ }_{t} e_{i j}+{ }_{t} \eta_{i j}$ 
where,

${ }_{t} e_{i j}=\frac{1}{2}\left({ }_{t} u_{i, j}+{ }_{t} u_{j, i}\right)$

${ }_{t} \eta_{i j}=\frac{1}{2}{ }_{t} u_{k, i}{ }_{t} u_{k, j}$

The nonlinear geometric equation is obtained by substituting into the first term of the Eq. (12), and approximately take $\delta_{t} \varepsilon_{i j}=\delta_{t} e_{i j}$, then, the first term of the Eq. (12) can be expressed as

$\int_{{ }^{t} V}{ }^{t+\Delta t}{ }_{t} \sigma_{i j} \delta_{t} \varepsilon_{i j}{ }^{t} d V=\int_{{ }^{t} V}{ }_{t} D_{i j k l} e_{t} e_{k l} \delta_{t} e_{i j}{ }^{t} d V+\int_{{ }^{t} V}^{t} \tau_{i j} \delta_{t} \eta_{i j}{ }^{t} d V+\int_{{ }^{t} V}^{t} \tau_{i j} \delta_{t} e_{i j}{ }^{t} d V$

Substitute Eq. (19) into Eq. (12):

$$
\begin{array}{r}
\int_{{ }^{t} V} \rho^{t+\Delta t} u_{i, t t} \delta u_{i}{ }^{t} d V+\int_{{ }^{t} V} \mu^{t+\Delta t} u_{i, t} \delta u_{i}{ }^{t} d V+\int_{{ }^{t} V}{ }_{t} D_{i j k l} e_{k l} \delta_{t} e_{i j}{ }^{t} d V+\int_{{ }^{t} V}^{t} \tau_{i j} \delta_{t} \eta_{i j}{ }^{t} d V \\
=\int_{{ }^{t} V}{ }^{t+\Delta t}{ }_{t}^{t} f_{i} \delta u_{i}{ }^{t} d V+\int_{{ }^{t} S_{\sigma}}{ }^{t+\Delta t}{ }_{t}{ }_{T} \delta u_{i}{ }^{t} d S-\int_{{ }^{t} V}^{t} \tau_{i j} \delta_{t} e_{i j}{ }^{t} d V
\end{array}
$$

Using Eq. (8) and according to the arbitrariness of node displacement variation $\delta u_{i}$, the solution equation of dynamic system equation is finally obtained:

$$
{ }_{t}^{t} \mathbf{M}{ }^{t+\Delta t} \ddot{\mathbf{u}}+{ }_{t}^{t} \mathbf{C}{ }^{t+\Delta t} \dot{\mathbf{u}}+{ }_{t}^{t} \mathbf{K} \mathbf{u}={ }^{t+\Delta t} \mathbf{Q}-{ }_{t}^{t} \mathbf{F}
$$

where, ${ }^{t+\Delta t} \ddot{\mathbf{u}}$ and ${ }^{t+\Delta t} \dot{\mathbf{u}}$ are the acceleration and velocity vectors of element nodes at time $t+\Delta t$, $\mathbf{u}$ is the displacement increment vector; ${ }_{t}^{t} \mathbf{M},{ }_{t}^{t} \mathbf{C}$ and ${ }_{t}^{t} \mathbf{K}$ are the mass, damping and stiffness matrix corresponding and referring to the configuration at time $t ;{ }^{t+\Delta t} \mathbf{Q}$ is the external applied nodal load vector at time $t+\Delta t,{ }_{t}^{t} \mathbf{F}$ is the vector of the nodal load equivalent to the element stresses corresponding and referring to the configuration at time $t$.

$$
\begin{aligned}
& { }_{t}^{t} \mathbf{M}=\sum_{e} \int_{{ }^{t} V_{e}} \rho \mathbf{N}^{\mathrm{T}} \mathbf{N}^{t} d V \\
& { }_{t}^{t} \mathbf{C}=\sum_{e} \int_{{ }^{t} V_{e}} \mu \mathbf{N}^{\mathrm{T}} \mathbf{N}^{t} d V \\
& { }_{t}^{t} \mathbf{K}={ }_{t}^{t} \mathbf{K}_{L}+{ }_{t}^{t} \mathbf{K}_{N L}
\end{aligned}
$$

where,

$$
\begin{aligned}
& { }_{t}^{t} \mathbf{K}_{L}=\sum_{e} \int_{{ }^{t} V_{e}}{ }_{t}^{t} \mathbf{B}_{L t}^{T} \mathbf{D}_{t}^{t} \mathbf{B}_{L}{ }^{t} d V \\
& { }_{t}^{t} \mathbf{K}_{N L}=\sum_{e} \int_{{ }^{t} V_{e}}{ }_{t}^{t} \mathbf{B}_{N L}^{T}{ }^{t} \tau_{t}^{t} \mathbf{B}_{N L}{ }^{t} d V
\end{aligned}
$$


${ }^{t+\Delta t} \mathbf{Q}=\sum_{e} \int_{{ }^{t} V_{e}} \mathbf{N}^{\mathrm{T} t+\Delta t}{ }_{t}^{t} \mathbf{f}^{t} d V+\sum_{e} \int_{{ }^{t} S_{\sigma}^{e}} \mathbf{N}^{\mathrm{T}}{ }^{t+\Delta t}{ }_{t} \overline{\mathbf{T}}^{t} d V$

${ }_{t}^{t} \mathbf{F}=\sum_{e} \int_{{ }^{t} V_{e}}{ }_{t}^{t} \mathbf{B}_{L}^{\mathrm{T}} d V \hat{\tau}^{t} d V$

where, the symbol $\mathrm{T}$ at the top-right corner represents the transpose of the matrix, for example, $\mathbf{N}^{\mathrm{T}}$ represents the transposition of the interpolation function matrix $\mathbf{N} ;{ }_{t}^{t} \mathbf{B}_{L}$ and ${ }_{t}^{t} \mathbf{B}_{N L}$ are linear and nonlinear strain-displacement transformation matrices; ${ }_{t} \mathbf{D}$ is the incremental material property matrix correspond to the configuration at time $t$; ${ }^{t} \tau$ is a matrix and ${ }^{t} \hat{\tau}$ is a vector of Cauchy stresses in the configuration at time $t$. All above matrix elements correspond to the configuration at time $t$ and are defined with respect to the configuration at time ${ }_{t} .{ }^{t+\Delta t}{ }_{t} \mathbf{f}$ and ${ }^{t+\Delta t} \bar{t} \mathbf{T}$ are the volume force matrix and surface force matrix at time $t+\Delta t$ and respect to the configuration at time $t$.

\subsection{Calculation of Damping}

Barbieri et al. [31] studied the damp of conductors by using experimental and numerical models, Rayleigh damp can be used to describe the damp of conductors was proposed. Rayleigh damping is a linear combination of mass matrix and stiffness matrix, and the expression is:

${ }_{t}^{t} \mathbf{C}=\alpha{ }_{t}^{t} \mathbf{M}+\beta{ }_{t}^{t} \mathbf{K}$

where, $\alpha$ is the mass damping coefficient and $\beta$ is the stiffness damping coefficient, which can be calculated by the vibration mode damping ratio:

$\alpha=\frac{2 w_{i} w_{j}\left(\varepsilon_{i} w_{j}-\varepsilon_{j} w_{i}\right)}{w_{j}^{2}-w_{i}^{2}}, \beta=\frac{2\left(\varepsilon_{j} w_{j}-\varepsilon_{i} w_{i}\right)}{w_{j}^{2}-w_{i}^{2}}$

where, $w_{i}$ and $w_{j}$ are the $i$ and $j$ order frequencies of the structure, respectively; $\varepsilon_{i}$ and $\varepsilon_{j}$ are the damping ratios of the $i$ and $j$ modes, respectively. Since the low-order frequency can better reflect the characteristics of the structure, it is generally taken as $i=1$ and $j=2$.

\subsection{Criteria for Icing Shedding}

In this paper, the icing element is considered to subject the horizontal wind load, gravity and inertia forces. The free body diagram of the icing element is shown in Fig. 10.

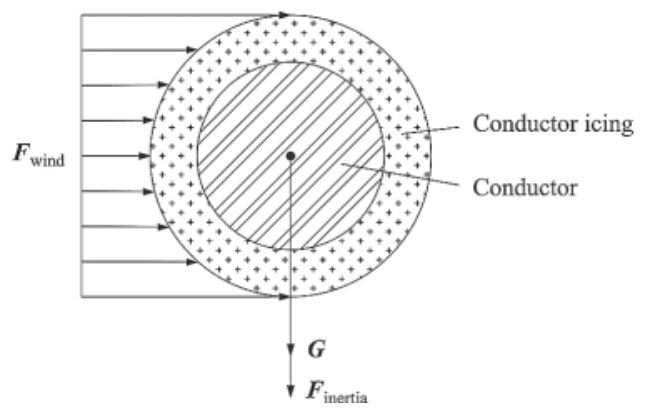

Figure 10: The free body diagram of the iced line 
The equivalent plastic strain failure criterion proposed by Kalman [32] based on strain and the tensile strength failure criterion proposed by Druez et al. [33] based on strength are two kinds of ice-shedding criteria that have been applied in numerical analysis. Phan et al. [34] and Laforte et al. [35] tested the bending strength and compression strength of the ice coating on the outside of the conductor (ground) wire, it is found that the shear deformation of the ice coating on the outside of the conductor (ground) wire could be ignored. They believed that the maximum tensile stress theory was more reasonable for the failure of the icing, so the failure criterion of tensile strength was adopted in this paper:

$\xi_{e} \geq \xi_{0}$

where, $\xi_{e}$ is the stress generated by wind load $\boldsymbol{F}_{\text {wind }}$, gravity load $\boldsymbol{G}$ and inertia force $\boldsymbol{F}_{\text {inertia }}$ of the icing element, $\xi_{0}$ is the tensile strength of the icing element.

Then, the implementation of the finite element analysis criteria is as follows:

(1) At the beginning of each time step, the finite element model of the wind-induced ice-adhesion transmission tower-line system is solved to obtain the stress $\xi_{e}$ of all icing element.

(2) The stress results $\xi_{e}$ of all icing element should be extracted in this paper, and compare with the critical tensile stress $\xi_{0}$. If the result satisfies the condition Eq. (31), the icing element will be "killed." Note that, when an element is "killed," the "DEATH" element is not really deleted from the model, but the stiffness of the element multiplies by a small reduction factor. The stiffness is reduced to a low value, the mass, damping and stress stiffness matrix, element stress and strain of the element are all reset to zero.

(3) The above two steps are repeated until all time steps of the specified solution time are completed.

\section{Dynamic Analysis of Wind-Induced Deicing of Tower Line System}

In order to study the dynamic characteristics of icing shedding of transmission tower-line system under wind load, a finite element model of two-span angle tower-line system with line rotation angle of $15^{\circ}$ is established in this paper. Additional ice element method is used to simulate icing of transmission line. The dynamic response of wind-induced ice shedding is compared and analyzed when the wind velocity is 10,15 and $27 \mathrm{~m} / \mathrm{s}$ (design wind velocity), and the line icing thickness is $0,10,20$ and $30 \mathrm{~mm}$, respectively. The dynamic response of the tower line system under several working conditions are compared and analyzed from several aspects, which include the displacement and stress at the midpoint of the conductors and ground wires, the maximum stress at the conductors and ground wires, the displacement at the top point of the transmission tower, the base reaction of the tower, and the maximum equivalent stress of the tower.

\subsection{Stress Response of Conductor and Ground Wire}

In the wind-induced icing shedding dynamic response analysis, the maximum stress time history of the conductor and the ground wire when the wind velocity is $27 \mathrm{~m} / \mathrm{s}$ is shown in Fig. 11. The maximum stress values of the conductor and the ground wire under various working conditions are shown in Tabs. 7-9. Due to the influence of icing shedding, the stress of conductor varies obviously in the first 20 seconds, and the stress of ground wire varies sharply in the first two seconds. The graphs and tables show that: (1) When the wind velocity is constant, the maximum stress of the line increases with the icing thickness; when the icing thickness is 
constant, the maximum stress of the line increases with the wind velocity. (2) When the wind velocity is $15 \mathrm{~m} / \mathrm{s}$ and the icing thickness is $20 \mathrm{~mm}$ and $30 \mathrm{~mm}$, the axial stress of the ground wire is $575.9896 \mathrm{MPa}$ and $753.3430 \mathrm{MPa}$ respectively, both of which have exceeded the maximum working stress of the ground wire. (3) When the wind velocity is $27 \mathrm{~m} / \mathrm{s}$ and the icing thickness is $20 \mathrm{~mm}$, the axial stress of the ground wire at $t=1.2 \mathrm{~s}$ is $1104 \mathrm{MPa}$, which reaches two times of the breaking stress of the ground wire. (4) When the wind velocity is $27 \mathrm{~m} / \mathrm{s}$ and the icing thickness is $30 \mathrm{~mm}$, the axial stress of the ground wire exceeds the tensile stress at $t=0.7 \mathrm{~s}$, the ground wire is broken, and the calculation is terminated.

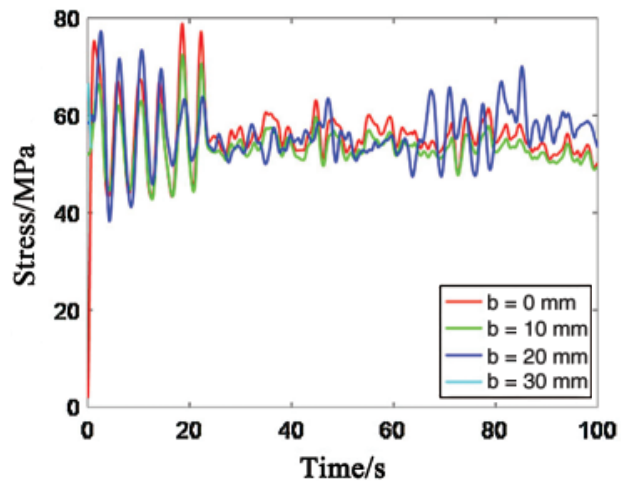

(a)

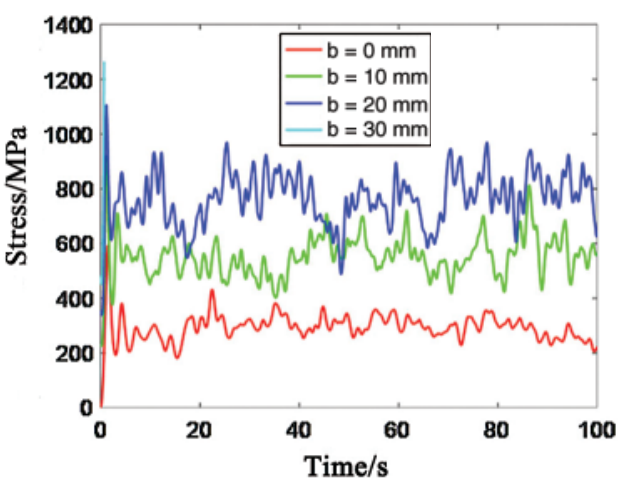

(b)

Figure 11: Maximum stress time history curve of conductor and ground wire at wind velocity of $27 \mathrm{~m} / \mathrm{s}$. (a) Stress time history of conductor. (b) Stress time history of ground wire

Table 7: Maximum stress of conductor and ground wire at wind velocity of $27 \mathrm{~m} / \mathrm{s}$ (MPa)

\begin{tabular}{lllll}
\hline & $b=0 \mathrm{~mm}$ & $b=10 \mathrm{~mm}$ & $b=20 \mathrm{~mm}$ & $b=30 \mathrm{~mm}$ \\
\hline Conductor & 66.4414 & 75.2828 & 77.2538 & - \\
Ground wire & 592.6363 & 919.5480 & 1104.5135 & - \\
\hline
\end{tabular}

Table 8: Maximum stress of conductor and ground wire at wind velocity of $15 \mathrm{~m} / \mathrm{s}$ (MPa)

\begin{tabular}{lllll}
\hline & $b=0 \mathrm{~mm}$ & $b=10 \mathrm{~mm}$ & $b=20 \mathrm{~mm}$ & $b=30 \mathrm{~mm}$ \\
\hline Conductor & 48.7836 & 54.7589 & 59.2100 & 66.5082 \\
Ground wire & 210.0323 & 391.8077 & 575.9896 & 753.3430 \\
\hline
\end{tabular}

Table 9: Maximum stress of conductor and ground wire at wind velocity of $10 \mathrm{~m} / \mathrm{s}(\mathrm{MPa})$

\begin{tabular}{lllll}
\hline & $b=0 \mathrm{~mm}$ & $b=10 \mathrm{~mm}$ & $b=20 \mathrm{~mm}$ & $b=30 \mathrm{~mm}$ \\
\hline Conductor & 46.54 & 52.42 & 58.78 & 64.58 \\
Ground wire & 201.44 & 228.94 & 351.62 & 451.89 \\
\hline
\end{tabular}




\subsection{Displacement Response of Conductor and Ground Wire}

Figs. 12 and 13 are the time history curves of the lateral and vertical displacement of the conductor and ground wire when the icing shedding occured by wind-induced vibration at the wind velocity is $27 \mathrm{~m} / \mathrm{s}$. Where the displacement in $\mathrm{X}$ direction represents lateral displacement, and the displacement in $\mathrm{Z}$ direction represents the displacement in vertical direction.

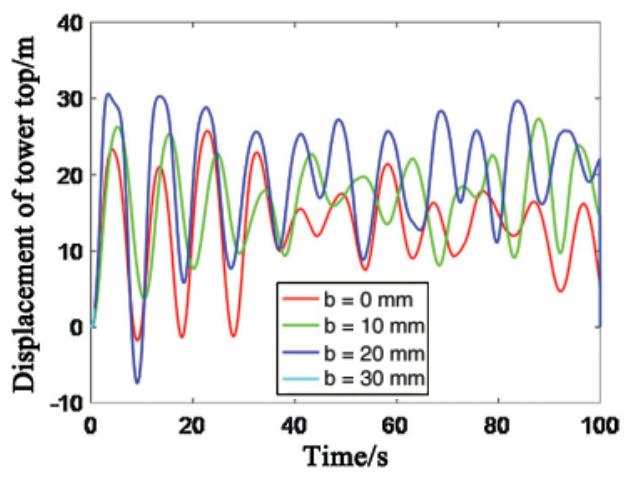

(a)

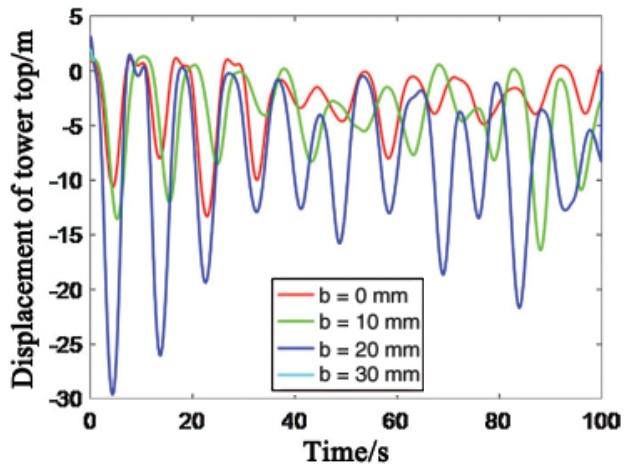

(b)

Figure 12: Time history of midpoint displacement of conductor at wind velocity of $27 \mathrm{~m} / \mathrm{s}$. (a) Lateral displacement. (b) Vertical displacement

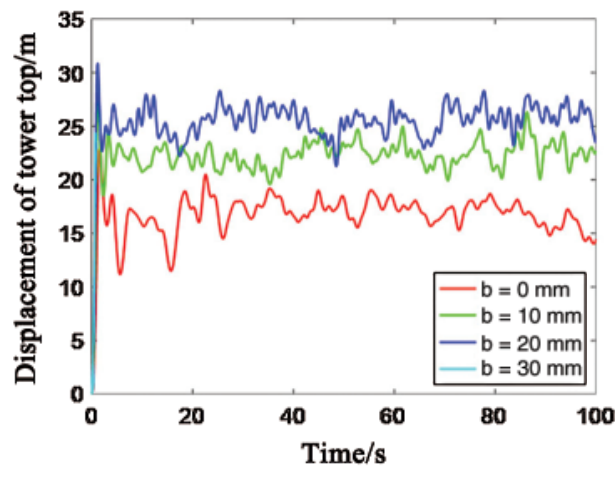

(a)

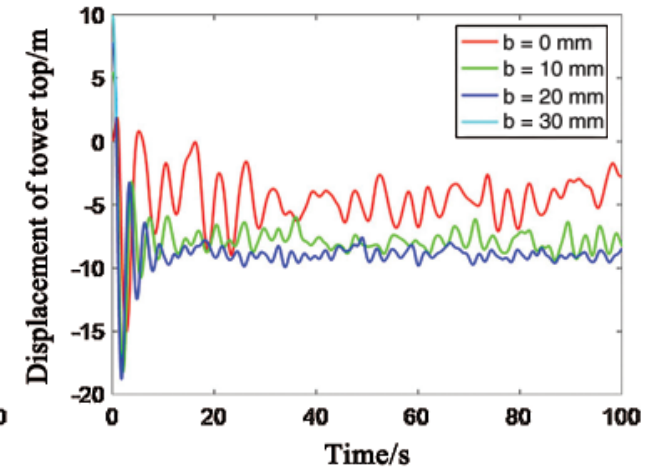

(b)

Figure 13: Time history of midpoint displacement of ground wire at wind velocity of $27 \mathrm{~m} / \mathrm{s}$. (a) Lateral displacement. (b) Vertical displacement

Under the action of wind vibration, the icing on the conductor is gradually deicing, and its lateral displacement and vertical displacement vary significantly in the first 20 seconds; while the ground wire is de-icing instantly under the action of wind, and its lateral displacement and vertical displacement vary significantly in the first 5 seconds. Subsequently, the influence of deicing of the guide wire is gradually smaller. Due to the existence of damping, the vibration amplitude of the line gradually decreases. However, due to the continuous effect of wind, the conductor and ground wire will not tend to be stable, but to a small amplitude of vibration. Tabs. 10-12 show the maximum amplitude of the line at wind velocity of 27,15 and $10 \mathrm{~m} / \mathrm{s}$. It can be seen from the table that the lateral and vertical amplitude of the line is larger due to 
the influence of the wind-induced icing shedding, while the amplitude of the guide wire without icing is smaller. As the thickness of icing increases, the maximum amplitude of ground guide line increases. For example, when the wind velocity is $27 \mathrm{~m} / \mathrm{s}$ and the ice thickness is $20 \mathrm{~mm}$, the maximum vertical displacement of the ground line is $35.2450 \mathrm{~m}$, which is $4.7847 \mathrm{~m}$ higher than that without ice, and the lateral displacement is $34.5700 \mathrm{~m}$, which is $6.9567 \mathrm{~m}$ higher than that without ice.

Table 10: Maximum amplitude of conductor and ground wire at wind velocity of $27 \mathrm{~m} / \mathrm{s}(\mathrm{m})$

\begin{tabular}{llllll}
\hline & Direction & $b=0 \mathrm{~mm}$ & $b=10 \mathrm{~mm}$ & $b=20 \mathrm{~mm}$ & $b=30 \mathrm{~mm}$ \\
\hline Conductor & X direction & 27.4820 & 27.3496 & 37.9332 & - \\
& Z direction & 12.1451 & 15.0844 & 26.4774 & - \\
Ground wire & X direction & 27.6133 & 32.1772 & 34.5700 & - \\
& Z direction & 30.4603 & 34.1570 & 35.2450 & - \\
\hline
\end{tabular}

Table 11: Maximum amplitude of conductor and ground wire at wind velocity of $15 \mathrm{~m} / \mathrm{s}(\mathrm{m})$

\begin{tabular}{llllll}
\hline & Direction & $b=0 \mathrm{~mm}$ & $b=10 \mathrm{~mm}$ & $b=20 \mathrm{~mm}$ & $b=30 \mathrm{~mm}$ \\
\hline Conductor & X direction & 10.2420 & 11.2668 & 17.1347 & 26.9841 \\
& Z direction & 1.4548 & 2.2344 & 6.0584 & 12.1614 \\
Ground wire & X direction & 19.5688 & 24.9479 & 28.1039 & 32.1582 \\
& Z direction & 11.8118 & 26.8054 & 33.1591 & 34.2201 \\
\hline
\end{tabular}

Table 12: Maximum amplitude of conductor and ground wire at wind velocity of $10 \mathrm{~m} / \mathrm{s}(\mathrm{m})$

\begin{tabular}{llllll}
\hline & Direction & $b=0 \mathrm{~mm}$ & $b=10 \mathrm{~mm}$ & $b=20 \mathrm{~mm}$ & $b=30 \mathrm{~mm}$ \\
\hline Conductor & X direction & 4.8250 & 5.2384 & 7.2684 & 9.0475 \\
& Z direction & 0.3664 & 0.4135 & 1.6466 & 2.6397 \\
Ground wire & X direction & 12.9885 & 19.7607 & 23.3929 & 25.7087 \\
& Z direction & 4.1247 & 14.0651 & 23.7848 & 30.8696 \\
\hline
\end{tabular}

\subsection{Displacement Response of Tower Top}

As shown in Fig. 14, the time history curve of the displacement of the top of the tower in dynamic analysis of wind-induced ice shedding is presented. Tab. 13 shows the maximum displacement of the top of the tower under different working conditions. We can see that the displacement of the top of the tower increases with the increasing wind velocity and ice thickness. According to the operation procedure for overhead transmission line, the maximum inclination of angle steel towers is 0.005 . In this paper, the height of the tower is $63 \mathrm{~m}$, and the displacement of the top of the tower should not exceed $0.315 \mathrm{~m}$. When the wind velocity is $27 \mathrm{~m} / \mathrm{s}$ and the icing thickness is $10 \mathrm{~mm}$ and $20 \mathrm{~mm}$, the maximum displacement of the top of the tower is $0.3380 \mathrm{~m}$ and $0.3910 \mathrm{~m}$ respectively, which are 1.073 times and 1.241 times of the critical value, and both exceed the allowable value of the top displacement. Therefore, the structure is not safe under these conditions. 


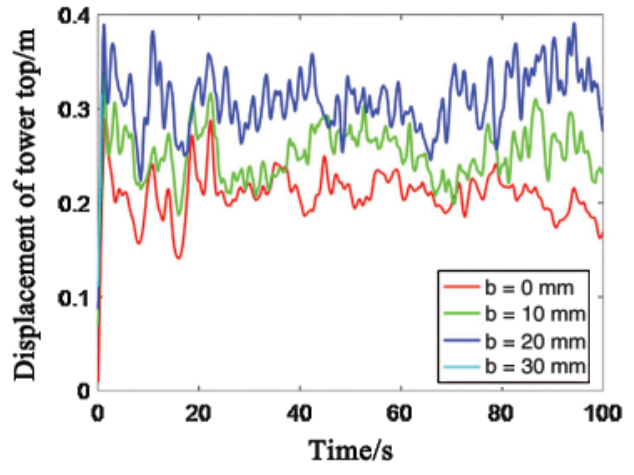

(a)

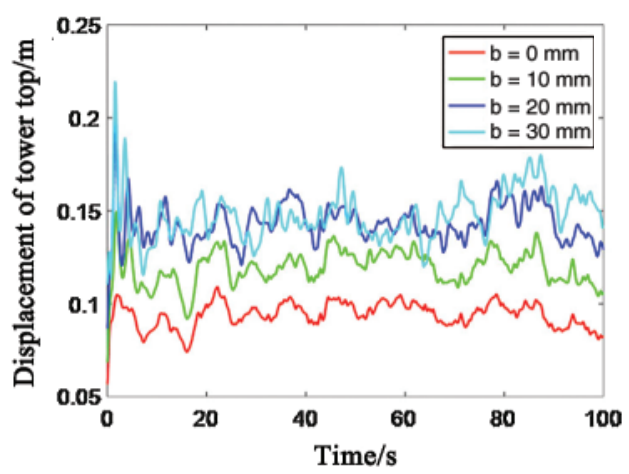

(b)

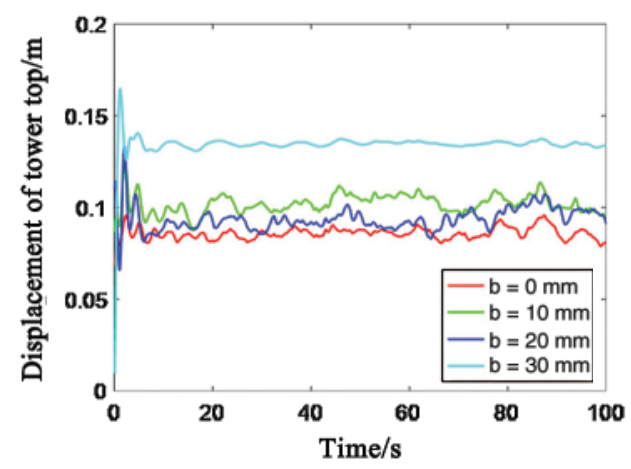

(c)

Figure 14: Time-history curve of tower top displacement under different working conditions. (a) Wind velocity is $27 \mathrm{~m} / \mathrm{s}$. (b) Wind velocity is $15 \mathrm{~m} / \mathrm{s}$. (c) Wind velocity is $10 \mathrm{~m} / \mathrm{s}$

Table 13: Maximum displacement of tower top under different working conditions (m)

\begin{tabular}{lllll}
\hline Wind velocity & $b=0 \mathrm{~mm}$ & $b=10 \mathrm{~mm}$ & $b=20 \mathrm{~mm}$ & $b=30 \mathrm{~mm}$ \\
\hline $10 \mathrm{~m} / \mathrm{s}$ & 0.0959 & 0.1250 & 0.1332 & 0.1646 \\
$15 \mathrm{~m} / \mathrm{s}$ & 0.1092 & 0.1496 & 0.1978 & 0.2193 \\
$27 \mathrm{~m} / \mathrm{s}$ & 0.2900 & 0.3380 & 0.3910 & - \\
\hline
\end{tabular}

\section{Conclusions}

To the best of our knowledge, this is the first attempt that the coupling dynamic response of the icing shedding and wind load for the transmission tower-line system is discussed in this paper, in addition, the dynamic characteristics of wind is included. The results of the constructor (ground) line stress, displacement of the constructor (ground) line and displacement of tower top under various wind speeds and icing thicknesses are discussed, and the conclusion are as follows:

(1) Because of the ice shedding, the stress of the conductor changes obviously in the first 20 seconds, and the ground wire changes sharply in the first two seconds. The maximum stress of the conductor (ground) wire increases with the increase of icing thickness and wind speed. When the wind speed is $15 \mathrm{~m} / \mathrm{s}$ and the icing thickness is $20 \mathrm{~mm}$, the axial 
stress of the ground line exceeds the maximum service stress. When the wind speed is $27 \mathrm{~m} / \mathrm{s}$ and the icing thickness is $30 \mathrm{~mm}$, the axial stress of the ground line exceeds the tensile stress at $t=0.7 \mathrm{~s}$ and the ground line is broken.

(2) The icing of the conductor (ground) wire is gradually deicing under the action of wind vibration. The lateral displacement and vertical displacement of the conductor change significantly in the first 20 seconds, while the ground line changes significantly in the first 5 seconds. Due to the existence of damping, the vibration amplitudes of the conductor (ground) wire are gradually reduced, however, oscillation is generated slightly as the wind continues to work.

(3) The displacement of tower top increases with the increase of wind speed and icing thickness. When the wind speed is $27 \mathrm{~m} / \mathrm{s}$, and the ice thickness exceeds $10 \mathrm{~mm}$, the maximum displacement of the tower top exceeds the allowable displacement of the tower top.

Funding Statement: This work is supported by the National Natural Science Foundation of China (Grant Nos. 41972323 and 51991362), Science and Technology Project of the 13th Five-Year Plan of Jilin Provincial Department of Education (Grant No. JJKH20190126KJ), and the Science and Technology Developing Plan Project of Jilin Province (Grant No. 20200201055JC).

Conflicts of Interest: The authors declare that they have no conflicts of interest to report regarding the present study.

\section{References}

1. McComber, P., Druez, J., Félin, B. (1990). Cable rime accretion measurements on a Laurentian mountain. Canadian Journal of Civil Engineering, 17(6), 1022-1032. DOI 10.1139/190-113.

2. Druez, J., Louchez, S., McComber, P. (1995). Ice shedding from cables. Cold Regions Science and Technology, 23(4), 377-388. DOI 10.1016/0165-232X(94)00024-R.

3. Savadjiev, K., Farzaneh, M. (2004). Modeling of icing and ice shedding on overhead power lines based on statistical analysis of meteorological data. IEEE Transactions on Power Delivery, 19(2), 715-721. DOI 10.1109/TPWRD.2003.822527.

4. Morgan, V. T., Swift, D. A. (1964). Jump height of overhead-line conductors after the sudden release of ice loads. Proceedings of the Institution of Electrical Engineers, 111(10), 1736-1746. DOI 10.1049/piee.1964.0285.

5. Jamaleddine, A., McClure, G., Rousselet, J., Beauchemin, R. (1993). Simulation of ice-shedding on electrical transmission lines using adina. Computers \& Structures, 47(4), 523-536. DOI 10.1016/0045-7949(93)90339-F.

6. Meng, X., Wang, L., Hou, L., Fu, G., Sun, B. et al. (2011). Dynamic characteristic of ice-shedding on UHV overhead transmission lines. Cold Regions Science and Technology, 66(1), 44-52. DOI 10.1016/j.coldregions.2011.01.005.

7. McClure, G., Lapointe, M. (2003). Modeling the structural dynamic response of overhead transmission lines. Computers \& Structures, 81(8), 825-834. DOI 10.1016/S0045-7949(02)00472-8.

8. Kálmán, T., Farzaneh, M., McClure, G. (2007). Numerical analysis of the dynamic effects of shockload-induced ice shedding on overhead ground wires. Computers \& Structures, 85(7), 375-384. DOI 10.1016/j.compstruc.2006.11.026.

9. Mirshafiei, F., McClure, G., Farzaneh, M. (2013). Modelling the dynamic response of iced transmission lines subjected to cable rupture and ice shedding. IEEE Transactions on Power Delivery, 28(2), 948-954. DOI 10.1109/TPWRD.2012.2233221.

10. Du, Y., Lu, X., Nie, Y. (2017). Research on dynamic response of ice layer shedding in line system. Journal of Hunan University (Natural Sciences), 44(7), 104-110. 
11. Yang, F., Yang, J., Zhang, H. (2014). Analyzing loads from ice shedding conductors for UHV transmission towers in heavy icing areas. Journal of Cold Regions Engineering, 28(3), 04014004. DOI 10.1061/(ASCE)CR.1943-5495.0000070.

12. Yan, B., Chen, K., Guo, Y., Liang, M., Yuan, Q. (2013). Numerical simulation study on jump height of iced transmission lines after ice shedding. IEEE Transactions on Power Delivery, 28(1), 216-225. DOI 10.1109/TPWRD.2012.2219324.

13. Zhang, M., Zhao, G., Wang, L., Li, J. (2017). Wind-induced coupling vibration effects of high-voltage transmission tower-line systems. Shock and Vibration, 2017(4), 1-34. DOI 10.1155/2017/1205976.

14. Ji, K., Rui, X., Li, L., Leblond, A., McClure, G. (2015). A novel ice-shedding model for overhead power line conductors with the consideration of adhesive/cohesive forces. Computers \& Structures, 157, 153-164. DOI 10.1016/j.compstruc.2015.05.014.

15. Ji, K., Rui, X., Li, L., Zhou, C., Liu, C. et al. (2015). The time-varying characteristics of overhead electric transmission lines considering the induced-ice-shedding effect. Shock and Vibration, 2015, 1-8. DOI $10.1155 / 2015 / 635230$.

16. Al-Bermani, F. G. A., Kitipornchai, S. (1993). Nonlinear finite element analysis of latticed transmission towers. Engineering Structures, 15(4), 259-269. DOI 10.1016/0141-0296(93)90029-4.

17. Hartog, J. P. D. (1932). Transmission line vibration due to sleet. Transactions of the American Institute of Electrical Engineers, 51(4), 1074-1076. DOI 10.1109/T-AIEE.1932.5056223.

18. Du, Y. X., Lu, X. L. (2015). Research on dynamic response of wind-induced ice-shedding of transmission tower-line system. Hunan Daxue Xuebao/Journal of Hunan University Natural Sciences, 42(11), $88-94$

19. Tian, L., Pan, H., Ma, R., Zhang, L., Liu, Z. (2019). Full-scale test and numerical failure analysis of a latticed steel tubular transmission tower. Engineering Structures, 208, 109919. DOI 10.1016/j.engstruct.2019.109919.

20. Fu, X., Wang, J., Li, H. N., Li, J. X., Yang, L. D. (2019). Full-scale test and its numerical simulation of a transmission tower under extreme wind loads. Journal of Wind Engineering \& Industrial Aerodynamics, 190, 119-133. DOI 10.1016/j.jweia.2019.04.011.

21. Tian, L., Guo, L., Ma, R., Gai, X., Wang, W. (2018). Full-scale tests and numerical simulations of failure mechanism of power transmission towers. International Journal of Structural Stability and Dynamics, 18(9), 1850109. DOI 10.1142/S0219455418501092.

22. Lu, J., Wang, Q., Wang, L., Mei, H., Yang, L. et al. (2019). Study on wind tunnel test and galloping of iced quad bundle conductor. Cold Regions Science and Technology, 160, 273-287. DOI 10.1016/j.coldregions.2018.12.009.

23. Rezaei, S. N., Chouinard, L., Langlois, S., Légeron, F. (2017). A probabilistic framework based on statistical learning theory for structural reliability analysis of transmission line systems. Structure and Infrastructure Engineering, 13(12), 1538-1552. DOI 10.1080/15732479.2017.1299771.

24. Yan, B., Liu, X., Lv, X., Zhou, L. (2016). Investigation into galloping characteristics of iced quad bundle conductors. Journal of Vibration and Control, 22(4), 965-987. DOI 10.1177/1077546314538479.

25. Gani, F., Légeron, F. (2010). Dynamic response of transmission lines guyed towers under wind loading. Canadian Journal of Civil Engineering, 37(3), 450-465. DOI 10.1139/L09-160.

26. Kim, J. W., Sohn, J. H. (2018). Galloping simulation of the power transmission line under the fluctuating wind. International Journal of Precision Engineering and Manufacturing, 19(9), 1393-1398. DOI 10.1007/s12541-018-0164-2.

27. Yang, F., Yang, J., Zhang, Z. (2012). Unbalanced tension analysis for UHV transmission towers in heavy icing areas. Cold Regions Science and Technology, 70, 132-140. DOI 10.1016/j.coldregions. 2011.07.008.

28. Petrovic, J. J. (2003). Review mechanical properties of ice and snow. Journal of Materials Science, 38(1), 1-6. DOI 10.1023/A:1021134128038.

29. Druez, J., Nguyen, D. D., Lavoie, Y. (1986). Mechanical properties of atmospheric ice. Cold Regions Science and Technology, 13(1), 67-74. DOI 10.1016/0165-232X(86)90008-X. 
30. Davenport, A. G. (1961). The application of statistical concepts to the wind loading of structures. Proceedings of the Institution of Civil Engineers, 19(4), 449-472. DOI 10.1680/iicep.1961.11304.

31. Barbieri, N., Júnior, O. H. D. S., Barbieri, R. (2004). Dynamical analysis of transmission line cables. Part 2-damping estimation. Mechanical Systems and Signal Processing, 18(3), 671-681. DOI 10.1016/S0888-3270(02)00218-2.

32. Kalman, T. (2007). Dynamic behavior of iced cables subjected to mechanical shocks (Ph.D. Thesis). Universite du Quebec a Chicoutimi, Canada.

33. Druez, J., Louchez, S., Bouchard, G. (1990). Study of ice shedding phenomenon on cables. Proceedings of the International Offshore Mechanics and Arctic Engineering Symposium, 4, 143-148.

34. Phan, C. L., McComber, P., Mansiaux, A. (1976). Adhesion of rime and glaze on conductors protected by various materials. Transactions of the Canadian Society for Mechanical Engineering, 4(4), 204-208. DOI 10.1139/tcsme-1976-0029.

35. Laforte, J. L., Phan, C. L., Felin, B., Martin, R., Quebec Univ, C. (1983). Adhesion of ice on aluminum conductor and crystal size in the surface layer. CRREL Special Report, Alaska. 